\title{
Authentic engineering problems in service mathematics assignments Principles, processes and products from twenty years of task design
}

\section{Schmidt, Karsten; Winsløw, Carl}

\section{Published in:}

International Journal of Research in Undergraduate Mathematics Education

Link to article, DOI:

$10.1007 / \mathrm{s} 40753-021-00133-0$

Publication date:

2021

Document Version

Peer reviewed version

Link back to DTU Orbit

Citation $(A P A)$ :

Schmidt, K., \& Winsløw, C. (2021). Authentic engineering problems in service mathematics assignments: Principles, processes and products from twenty years of task design. International Journal of Research in Undergraduate Mathematics Education. https://doi.org/10.1007/s40753-021-00133-0

\section{General rights}

Copyright and moral rights for the publications made accessible in the public portal are retained by the authors and/or other copyright owners and it is a condition of accessing publications that users recognise and abide by the legal requirements associated with these rights.

- Users may download and print one copy of any publication from the public portal for the purpose of private study or research.

- You may not further distribute the material or use it for any profit-making activity or commercial gain

- You may freely distribute the URL identifying the publication in the public portal 


\section{Authentic engineering problems in service mathematics assignments: Principles, processes and products from twenty years of task design}

Karsten Schmidt ${ }^{1}$ and Carl Winslø ${ }^{2}$

${ }^{1}$ Technical University of Denmark, learn T, DTU Compute, Denmark, ksch@dtu.dk; ORCID 0000-0001-8313-2241

${ }^{2}$ University of Copenhagen, IND, Faculty of Science, Denmark, winslow@ind.ku.dk; ORCID 0000-0002-9799-0340

\section{ACKNOWLEDGEMENTS}

We thank all the colleagues at DTU who have generously offered time and materials for our study, and in particular the following, who participated in interviews: Martin P. Bendsøe, Steen Markvorsen, Luise Theil Kuhn, Rasmus Bjørk, Ulrik Engelund Pedersen, Peter Gross, Toke Rammer Nielsen, Frank Pedersen and Hans Henrik Knudsen. 


\title{
Authentic engineering problems in service mathematics assignments: Principles, processes and products from twenty years of task design
}

\begin{abstract}
A central problem in undergraduate mathematics education for future engineers consists in the perceived and actual relevance of the mathematical content. One strategy to strengthen both is to let students experience how that content appears in posing and solving authentic problems from the field of engineering which the students have signed up to study. This paper proposes a way to develop such a strategy, both in terms of theoretical precision (e.g. to clarify what "authentic" could mean in this context), and in terms of the institutional and epistemological conditions and constraints for realizing the strategy. The paper is based on cases and formats developed over twenty years at the Technical University of Denmark.
\end{abstract}

Keywords. Authentic engineering problem, Calculus, Linear Algebra, didactic transposition

\section{INTRODUCTION}

Let us consider a setting which has replicas at technical universities throughout the world: freshman courses in Calculus and Linear Algebra which are shared by a large number of bachelor programmes in engineering, and which are taught by faculty whose main academic background is in pure or applied mathematics. It is a genuine, shared desire of teachers and students that the course involves experiences of how the contents of the course appear in posing and solving engineering problems. But this is not an easy wish to fulfil, for several reasons: the variety of specializations that students engage in, the meaning of real engineering problems (for any of these specializations), the limited mathematical scope of the course (does the problem and its solution support course goals?), and the academic background of the teachers of the course (do they even know what a real engineering problem is?). We also assume that teachers and students agree that it does not suffice that teachers merely show students such problems and their solutions - since the mathematical contents are likely to become relevant only in actually working on the problem. The whole challenge can then be considered a problem of task design (Watson and Ohtani, 2015): crafting feasible yet challenging assignments for students, which allow them to work with real engineering problems that involve mathematical theory and techniques from the course, both in the solutions and in their formulations. Our main motivation for addressing this specific task design problem comes from a wider concern about the (possibly widening) gaps that are perceived to exist between engineering students' official mathematics curriculum, the mathematical needs in engineering courses, and the extent to which students' preparation satisfies those needs. It appears evident that a "close collaboration between engineering and service mathematics" (Harris et al., 2015, p. 330) is necessary to counteract this tendency.

We note that a task is, here, to be understood as an assignment to be worked on by students, and that such a task may in fact involve several subtasks. We also note that students' work on the tasks in question will most likely need to be supported by various forms of teacher support 
(e.g. supervision), and as all other serious goals of the course, be aligned with how the students are assessed. Thus, at least some part of the course goals, teaching and assessment needs to be adapted to fit the tasks developed. This may not be a trivial requirement. Several studies have pointed out that standard practices of teaching, learning (e.g. Pohjolainen et al., 2018; Hardy, 2009) and assessment (e.g. Bergqvist, 2007) in introductory mathematics courses, are massively focused on routine mathematical techniques for standard problems (such as solving systems of linear equations or computing multiple integrals).

The main purpose of the paper is to advance our grasp of the more theoretical challenge of strengthening the perceived and actual relevance of mathematics education for engineering students, and ensuring a strong anchoring of our proposals in actual practice. Our proposal should make sense for any context in which one has decided to maintain an ambitious and internally connected teaching of mathematical contents at the early stage of the engineering programme, as opposed to the alternative "just in time" approach (cf. Mustoe, 2002) in which elements of mathematics are taught only as they become necessary in courses whose main focus is some engineering discipline. With such a decision, there is a real risk that mathematics will appear isolated and irrelevant to some students and teachers of engineering (Flegg, Mallet and Lupton, 2012), with frequent attrition and achievement problems as a main symptom (Baillie and Fitzgerald, 2000). Several studies (e.g. Härterich et al., 2012; Kumar and Jalkio, 1999) have focused on attempts to increase the visible connections, with innovative design of mixed tasks as a common strategy. In particular, Wolf and Biehler (2016) designed and experimented application oriented exercises for use in mathematics teaching to mechanical engineers. It is interesting to note the strong alignment between the design principles used in this research project (cf. also Wolf, 2017) and the didactic variables which we identify in this paper (Table 1), to make sense of a longstanding and spontaneous practice in a similar context.

In this paper, we present two closely related approaches to this problem of task design. First, we give a theoretical clarification of the nature of the tasks to be developed (involving both real engineering problems and course relevant mathematical contents). Second, and in close connection to the first point, we propose an institutional analysis of the challenges involved in creating such tasks and organising the students' work with them, including assessing the learning outcome. Both approaches are heavily anchored in twenty years of experience with so-called "projects" in the context of the course Mathematics 1 , taken each year by more than 1200 students from 19 different engineering programmes at the Technical University of Denmark.

The paper is structured as follows: we first present our theoretical framework and research questions, which will put the somewhat elusive ideas of real engineering problems, mathematical contents, and institutions (with different relationships to both) on firmer ground. Then follows the two main sections of the paper: we first present a concrete set of didactic variables for analysing tasks involving engineering problems, and the institutional organisation of their design, based on the case of the Technical University of Denmark. The following section presents an in-depth analysis of the design and maintenance of some concrete cases of projects 
found in this context. We return to what can be said about the more abstract research questions, in light of these two main sections.

This paper is an elaboration of a shorter conference article (Schmidt and Winsløw, 2018), in which we presented one of the cases in this paper, along with the analysis of its didactical variables.

\section{THEORETICAL FRAMEWORK AND RESEARCH QUESTIONS}

The theoretical framework is based on the Anthropological Theory of the Didactic (ATD, cf. Chevallard, 1999; 2019). We first explain the basic theoretical notions we need (institutions; didactical transposition; task design and didactic variables). Then we proceed to our definition of "authentic problems from engineering" and the way we have organised the process of task design involving such problems, in particular the contribution from different institutions in the didactic transposition. Finally we present the research questions which the remainder of the paper seeks to tackle.

\section{Didactical Transposition between Institutions}

The notion of institution is central to the anthropological approach, and differs in some regards from commonplace use of the term. Within ATD the notion is both quite general and abstract: it is a system of positions which a human being may occupy relative to some objects. In a didactical context the objects are typically knowledge objects, and the positions which people may occupy within a didactical institution are more or less defined by what these people are expected to be able to do with the knowledge objects. For instance, a first year course in mathematics may be considered as an institution which carries positions such as lecturers, teaching assistants, and students; and these positions are then defined by what people occupying those positions are supposed to do with the knowledge objects which are roughly what we sometimes call the contents of the course. We note here that we do not make any strong assumptions about the knowledge objects - they are merely what members of a given institution regard as important elements of the institution's activity. The notation $R_{I}[p, O)$ is sometimes used to indicate the relationship of a position $p$ to the object $O$ within the institution $I$ (Chevallard, 1991). The point is that $I, p$ and $O$ get their meaning from each other: the institution consists of the positions $p$, these are defined by specific relationships held to $O$ within $I$, and the objects $O$ consist of entities that are used to define at least some positions within $I$. In this paper we do not use this notation, but certainly the corresponding idea.

Certain institutions have a higher permanence than others. In the context of didactics, we are naturally concerned with institutions of the school type, that is, institutions where knowledge is taught. This evidently includes universities when viewed as teaching institutions, with teachers and students at various levels and specializations. However, it is a crucial feature of ATD to insist - from its early beginnings (Chevallard, 1991) - on the crucial interplay of school type institutions with scholarly institutions, defined roughly as institutions in which knowledge is produced. This interplay is studied as a transposition of knowledge objects from the scholarly institution to the teaching institution, which often implies subtle adaptations and changes in 
those objects over time - we can, for instance, think of the way Calculus is taught and learned in contemporary university courses, in contrast with the ways it was discovered and continues to play a role in scholarly contexts such as mathematics and physics. We notice that the scholarly institutions also have a relatively high degree of permanence, despite evident historical evolutions, and that they include universities when viewed as research institutions, with scholars in different positions, including various levels and specializations. We also note that specific subsets of positions within a university also form institutions, both of the school type (e.g. a course) and of the scholarly type (e.g. a department).

Considering the role of mathematics in engineering education globally, we can say that two types of institutions within the university are at least potentially relevant: that of mathematics broadly speaking, and that of engineering. These institutions comprise both scholarly and school-type ones, such as research groups and courses; entities termed "departments" often involve both scholarly and school-type purposes, but a closer look at the knowledge objects involved in these purposes reveal that transposition phenomena are also at play. What does the didactic transposition look like in the case of mathematics courses for engineers? How does it relate to other parts of the engineering programme? While it is of course impossible to say something universally valid about this, we can describe a common situation in general and somewhat ideal terms (cf. Figure 1): first, certain parts of scholarly mathematics are selected as knowledge to be taught in the programme, and this selection is at least to some extent, perhaps mainly historically, coordinated with the engineering knowledge to be taught (notably in terms of mathematics needed there). This part of the didactical transposition is called external because it happens outside the school institution, which we consider here as courses and other settings of university teaching. On the other hand, the "knowledge to be taught" is again transposed within the school institutions, as teachers in various positions make choices of how to frame the work of students, and otherwise carry out their teaching; this involves, in particular, crafting or choosing crucial objects such as texts and assignments that students should work with. This part of the transposition is carried out by the teachers and is thus internal to the school institution. In the case of the mathematics course, this part often involves little or no interaction with the internal transposition of engineering knowledge, so that the internal transpositions happen in parallel (cf. Figure 1; we note that there is of course also important interactions, in particular transpositions, between the two scholarly fields, and that "scholarly engineering" is here to be conceived broadly and not as limited to research institutions, cf. Castela and Romo-Vásquez, 2011). 


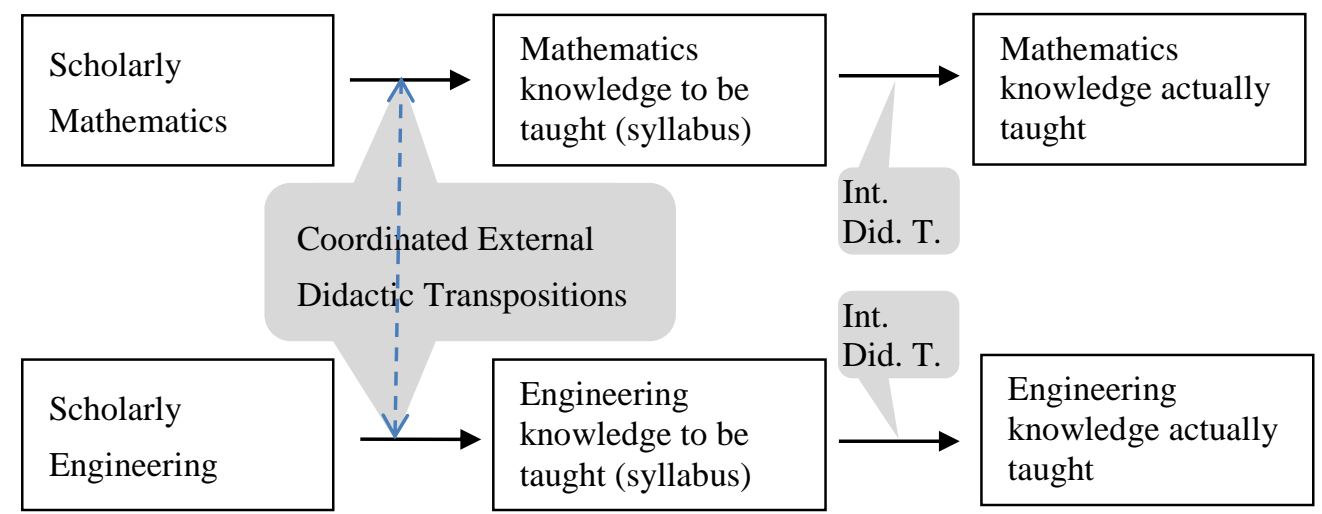

Figure 1. The parallel model for didactic transposition in engineering education.

The potential problem with the parallel model is that the student position in mathematics and engineering courses involve, naturally, the same persons, and we suppose that the courses share certain knowledge objects. Further, we expect that emerging relationships to these, as developed in the mathematics course, will be relevant to knowledge objects and further relationships developed in the engineering courses. However, the relationships developed in any course depends crucially on the internal didactic transposition, that is, on the activities (tasks, readings, explanations, etc.) which students engage in, to become familiar with the knowledge objects. As we noted, the internal didactic transpositions are developed in parallel, by different groups of teachers.

\section{Authentic Problems of Engineering and Task Design}

The idea for task design pursued in this paper can now be identified roughly as:

- identifying knowledge objects (problems, theories, results, methods etc.) from a field of scholarly engineering, which are central in the external transposition at the level of the programme

- creating assignments for student work where these objects interact crucially with central knowledge objects that are central to the mathematics course.

In terms of figure 1, this can be thought of as a bypass operation from the lower left corner (scholarly engineering) to the upper right (the actual mathematics course).

We define an Authentic Problem from Engineering (APE) as a problem which comes from current research and innovation in some specific institution of scholarly engineering - one which members in this institution have a recent or current relationship to. When creating a student assignment based on an APE, methods and results from the scholarly institution are clearly involved. Such an assignment - which we call an APE-A - will also form part of the internal didactic transposition of the mathematics course, and must be viable in this context. The APE-A must, in particular, be consistent with the course goals. Therefore, the elaboration of an APE-A requires also to involve the relationship of experienced teachers with knowledge objects from the school institution. As few or no positions in the school institution have strong relationships with the APE and its associate objects, one will have to imagine a process of task design that involves also the relevant scholarly institution, and at least two steps. These steps 
are outlined in Figure 2 (up to version 1). A draft for an APE-A is elaborated by an engineering scholar with some familiarity with the mathematics teaching institution, for instance as a former student or perhaps even as an instructor. The draft is subsequently revised or rewritten by experienced teachers, and possibly further revised in the light of first experiments. This second step depends on the degree to which mathematics teachers have - or develop - a relationship to the APE which is consistent with that of the engineering scholar; since this will typically depend on the first draft, produced in the engineering institution, this first draft serves a very specific purpose (similar to external didactic transposition).

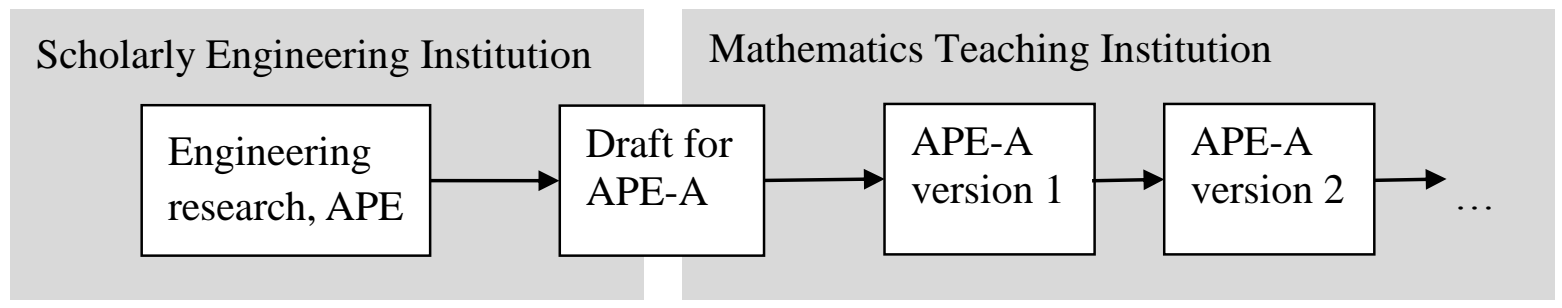

Figure 2: A model for shared design of APE-based projects.

\section{Didactic Variables}

The second (and subsequent) steps of the APE-A design requires taking into account the conditions and constraints of the school institution as a whole, in this case the mathematics course for which in APE-A was constructed. This requires explicit control of how the APE-A conforms to central goals and constraints in the course, in other words, task design depends on the "identification and judicious tuning of key didactical variables which influence the particular character of a task, the approaches available to it, and the pathways through which these unfold" (Ruthven, 2018, p. 315). Here, a didactic variable is defined as a characteristic property of a student assignment which contributes to determine the assignments' qualities both in the sense of consistency with course goals, and in the sense of potentially supporting students' achievements of them, as well as contributing to the assessment of this achievement. In teachers' everyday work with task design, such variables may only to some extent be defined explicitly, but the involvement of knowledge objects that are at least partially external to the teachers' institutions, seems to require specific vigilance and explicitness.

\section{Research Questions}

We can now formulate the research questions that are investigated in the present paper:

RQ1. How could the identification of APEs be organised, given the common academic and institutional distance between university mathematics teachers and engineering scholars?

RQ2. How can one organise the design of APE-As, for use in a service mathematics course? (Here, we assume that some collaboration between mathematics teachers and engineering scholars is required in order to ensure both authenticity and smooth integration in the course.) $\mathrm{RQ3}$. What didactic variables can be relevant to the construction of an APE-A?

These questions are obviously impossible to investigate independently of specific institutions and cases, and the empirical part of this paper is based on one such context, which we describe 
shortly in the next section. Still, by drawing on principles formulated in this context, as well as on the cases presented in greater detail, we will be able to formulate practical (while still somewhat hypothetical) answers that could be adapted to other, similar contexts.

\section{CONTEXT AND METHODOLOGY}

The context based on which we investigate the three research questions in this paper is the course Mathematics 1 (hereafter Mat1), taught at the Technical University of Denmark since 2000. The university is one of the most prestigious Schools of Engineering in Europe, and by far the largest in Denmark. Mat1 is the basic mathematics course for 19 different B.Sc.Eng.programmes at the university, catering to more than 1200 students per year. The course occupies $1 / 3$ of the students' time during the first year, and covers complex numbers, basics of linear algebra, ordinary differential equations including linear systems, and multivariate and vector calculus up to Gauss' theorem. Besides ensuring a technical foundation for later work, the university also considers a common course on mathematics as important to the formation of an engineer identity shared across specializations.

Most of the course is quite traditional, however with intense use of the Computer Algebra System Maple. Exercises with easy applications to engineering occur. However, during the last four weeks of the course, the students work on what is called a "project". This is based on an assignment containing about 10-30 more or less challenging tasks, ideally an APE-A (more details will follow). Each assignment is presented in a text of varying extent (ranging from 4 to 29 pages, averaging 11); it is the contents and genesis of these texts which we aim to analyse in this paper. The students do the projects in groups, hand in a report of about 20-50 pages, and defend their work during an oral exam, which accounts for $25 \%$ of their grade. Note that in this paper we refer to the work done by the students as the project, while the text presenting the tasks they solve is called an assignment.

The groups can choose their assignment from a list of 4-5 possibilities, in part depending on the study programme, with titles like those shown in Table 2 . As the titles suggest, the assigned problems come from many different areas of Engineering. Every year, new assignments are added and some are dropped, and the details of retained assignments are updated based on teachers' experiences. The identification and elaboration of new APEs is a particularly delicate undertaking, and we present our findings on this in the next section, which can be considered case-based answers to RQ1 and RQ2. The assignments are naturally also quite different, and the properties in terms of didactical variables are presented in the next section, as first answers to RQ3.

Our text is a representation of our work with a large number of documents, including old and newer assignments and correspondences surrounding their design and revision (for the assignments analysed in depth here), and also nine interviews with key actors in Mat1, carried out to clear up specific features of the APE-A design process, especially in slightly older cases (cf. acknowledgements). Seven of the interviews were long due to the importance of the informants' implication, and were sound recorded to retain the details. The interviews are not 
analysed or quoted in this paper, but were used to supply and verify details of the presentation of the process. The first author's role as course organiser for the past 10 years is evidently also drawn on, while the collaboration with the second author (from another university) has been deliberately used to select observations rooted in documents and interviews. The didactical variables identified to answer RQ3 were already presented at the INDRUM conference in 2018 (Schmidt and Winsløw, 2018), and are further consistent with the data presented in the next section.

\section{DESIGN AND CHARACTERISTICS OF APE-A}

The definition of an APE given above is deliberately close to the somewhat broader idea which has been pursued in Mat1 since the year 2000. Authenticity is related, for both teachers and students, to a specific institution of scholarly engineering, and also - more vaguely but no less importantly - to the future profession of the students (which, of course, cannot be predicted or assumed to be the same for all students, even within one specific B.Sc.Eng.-programme). In practice, basing the APE-A on a problem from an engineering discipline - which, at DTU, also includes more basic research - is considered as a way to introduce tasks which the students, in principle, can imagine occurring in a future work assignment as engineers. To cater to the variety of B.Sc.Eng.-programmes, it has from the beginning been a priority to seek ideas for APE candidates from similar variety of departments at DTU. An obvious obstacle is that faculty members from these departments are usually deeply submerged in their own research and teaching, and are not likely to prioritise contributing to teaching at other departments (in casu, mathematics). One evident challenge for mathematics faculty is therefore to motivate these colleagues to help constructing and maintaining a sufficient inventory of APE-A. For the mathematicians responsible for Mat1, the motivation is more evident, given the usual challenges from students (and occasionally, engineering faculty) to explain what use the material of the course would have for them beyond passing the mandatory course (which, for most, is not easy). It was evidently a strong motivation for the introduction of APE-A to give the students a glimpse of what such use could be.

In the first years of implementing projects in the course, a number of other challenges still remained: not all assignments were based on APEs in any sense (but were purely mathematical) and a considerable uncertainty, concerning the autonomy one could expect in students' work and from their supervisors (teaching assistants), can also be noticed. The latter has to do with quite different levels of detail and information provided to the students. We first describe the principles elaborated based on these first experiences, and then return to efforts made to engage faculty from engineering disciplines in the crafting of APE-A.

\section{Practical rules for APE-A design}

We can summarize, in four practical rules, the principles that were made explicit (in various sources, including interviews looking back on the first few years of experience, as well as internal mails) by the responsible teachers of Mat1. The purpose of these principles was to give potential co-authors of APE-A a clear impression of what was expected. Although we do not 
quote verbatim from the sources we formulate the principles in present tense to reflect that they are still part of the shared ideas underlying the design work:

1. The central challenges for students must be mathematical in nature - too often, one fails in attempts to make students simultaneously learn mathematics and some more or less (to them) new material from another discipline. The students get stuck and do not understand the questions properly in this situation, unless a supervisor is at hand and can explain it further to them. Thus, APE-As must introduce all necessary elements (e.g. from physics or chemistry) and also show, in relatively high detail, how the mathematics that students know can apply to these elements.

2. From 1. it follows that the mathematical model is given in the APE-A. This can be done gradually, by asking the students to work with key steps in its construction, or they can be asked to verify or try out the model if it is given in its finalised form.

3. In most cases, the mathematical content already learned in the course does not suffice to formulate a full APE. Then, one begins with a special (toy) case which the students can quickly engage with, based on mathematics they know. Subsequently, the model is gradually made more realistic, through introducing new mathematical techniques related to known ones, or the full problem is tackled by using numerical methods and other methods which involve more advanced features of the Computer Algebra System (Maple) that is used throughout Mat1.

4. A typical APE-A will have the following structure: first, the APE is introduced in the language of the scholarly domain it comes from, but with full explanation of all terms. Then follows a mathematization in which the mathematical model is built up using symbols, formulae etc. known from Mat1. Through a series of mathematical tasks, of rising complexity and difficulty, the APE is solved (at least in some special or approximate fashion). The APE-A often ends with more open-ended questions (which, it is understood, not all students may be able to solve fully, and where all attempts are valued).

As a result of applying these principles, the APE-A share a number of important properties (especially, it is clear that the main challenges they offer to students are in fact relevant to Mat1). Their contents and authors are, on the other hand, so different that there is still considerable diversity in length and structure of the assignment texts. A consensus has built over the years that it is not possible to ensure equal relevance, interest and difficulty of all APE$\mathrm{A}$, and that equal difficulty is at any rate not a realistic or reasonable aim to strive for. The frustration this can create among students is to some extent eased by the promise and practice of taking the difficulty of the assignment into account when assessing the quality of the students' performance.

\section{Practical measures to identify an APE and draft APE-A}

We now proceed to the institutional and practical strategies developed, for Mat1 and in the specific context of DTU, to identify an APE and initiate the draft of an APE-A (cf. Figure 2). Besides the challenges of motivating faculty of engineering departments, outlined above, it must also be mentioned that these often have only a superficial idea of the contents, form and 
ambitions of Mat1, even if it is a mandatory course for all B.Sc.Eng.-programmes at the university - some, especially those recruited from abroad, do not even know the course exists. The Department of Mathematics at DTU decided, in 2004, to invest massively in the creation of a larger and more viable inventory of APE-As. A leading professor from the department was appointed to organise a campaign to identify new APE candidates, and oversee the process of drafting corresponding APE-A texts. This constituted the full teaching duty of this professor during the years 2004-2006, and the task required both strong disciplinary and personal competences, including organizational talent and a thorough acquaintance with the contents and students of Mat1, as well as with the many programmes it serves. A total of 13 new APE-A were produced. The above explicit principles were useful in all phases of the work. Often, it was necessary to address the management of specific departments from which contributions were deemed necessary; in other cases, the leading professor was able to draw on his own research and collaborations with faculty from these departments.

When the campaign has identified a possible APE, a collaboration about the drafting of the corresponding APE-A has to be organized with one or more partners from an engineering department. Much depends on the nature of the APE and the partners' experience in drafting text with mathematical contents. In some cases, the first draft made by the partner only needs few adaptations and add-ons to be ready for use; in other cases, the partners deliver just a few pages of hand-written notes, and the leader or colleagues from the Department of Mathematics then undertake the drafting process with the external partner as a kind of consultant. When an APE-A has been used with students, in a first or revised version, a systematic and yearly renewed effort is invested to collect and make use of the comments from students and their supervisors, in order to revise or renew the assignments accordingly. The identified problems range from excessive difficulty to outright mistakes or errors in the APE-A, and in some cases, parts of an APE-A become the basis for a new APE and the drafting of a very different or entirely new APE-A. The creation of new programmes - such as the recent B.Sc.Eng.-programme with living systems as a possible specialization - led to a new APE-A on "Size-structured fish population" which can also be used in other programmes. In such cases, the partner departments are motivated to invest in the collaboration in view of attracting students to a given specialization.

To get beyond these generalities, we now describe, in more detail, the institutional process behind the design of two specific APE-A; their contents will be revisited in terms of didactical variables in the following section.

\section{Case 1: Analytical modeling of 2D Halbach permanent magnets}

The abstract APE behind this assignment is to compute and control the magnetic field induced by a so-called Halbach magnet, consisting of one or more tube shaped permanent magnets (cf. Halbach, 1980 and R. Bjørk et al., 2014). We first outline the mathematical model in order to give the reader a sense of the Mat1 contents involved. The permanent magnetic field (remanence) generated by the material, is modeled by the 2 dimensional vector field 


$$
\mathbf{B}_{\mathrm{rem}}=\left(\begin{array}{c}
B_{\mathrm{rem}, r} \\
B_{\mathrm{rem}, \theta}
\end{array}\right)=B_{\mathrm{rem}}\left(\begin{array}{c}
\cos (p \theta) \\
\sin (p \theta)
\end{array}\right)
$$

where $p$ is an integer indicating the direction and number of symmetries of the magnetic field, which are chosen according to the specific purpose of the magnet. Figure 3 shows cross sections of a Halbach magnets; for case $p=1$ the magnet induces a homogeneous field inside the tube, while for the case $p=-3$ the field induced is outside.
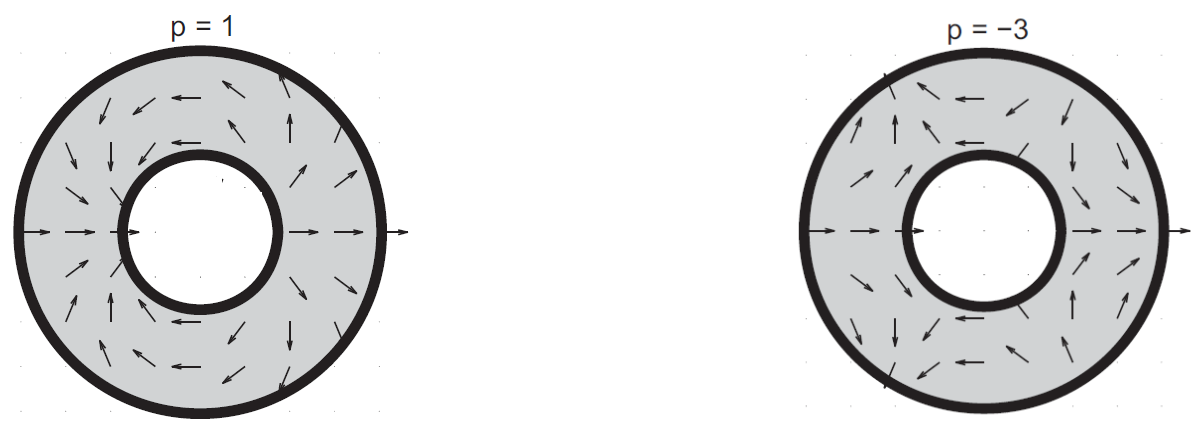

Figure 3. Halbach magnets with inner (left) and outer (right) fields.

The students are led through the deduction from Maxwell's equations of the central model to answer the APE, namely a second order partial differential equation of the form

$$
-\nabla^{2} \mathbf{A}=\boldsymbol{\operatorname { R o t }}\left(\mathbf{B}_{\mathrm{rem}}\right)
$$

where $\mathbf{A}$ is a vector potential for the induced magnetic field that is to be investigated. Using the boundary conditions that come from the geometry of the magnet, the students are then asked to investigate two concrete APEs. The first concerns the design of an MRI scanner (Figure 4, left), where the dimensions of the Halbach magnets (with $p=1$ ) are to be found so that the inner homogenous field equals that obtained in a scanner built with a traditional electromagnetic coil. In the second the students are to design a motorcycle clutch involving two concentric Halbach magnets (Figure 4, right with $p=2$ and $p=-2$ ), so as to optimize the induced moment of force between the magnets.
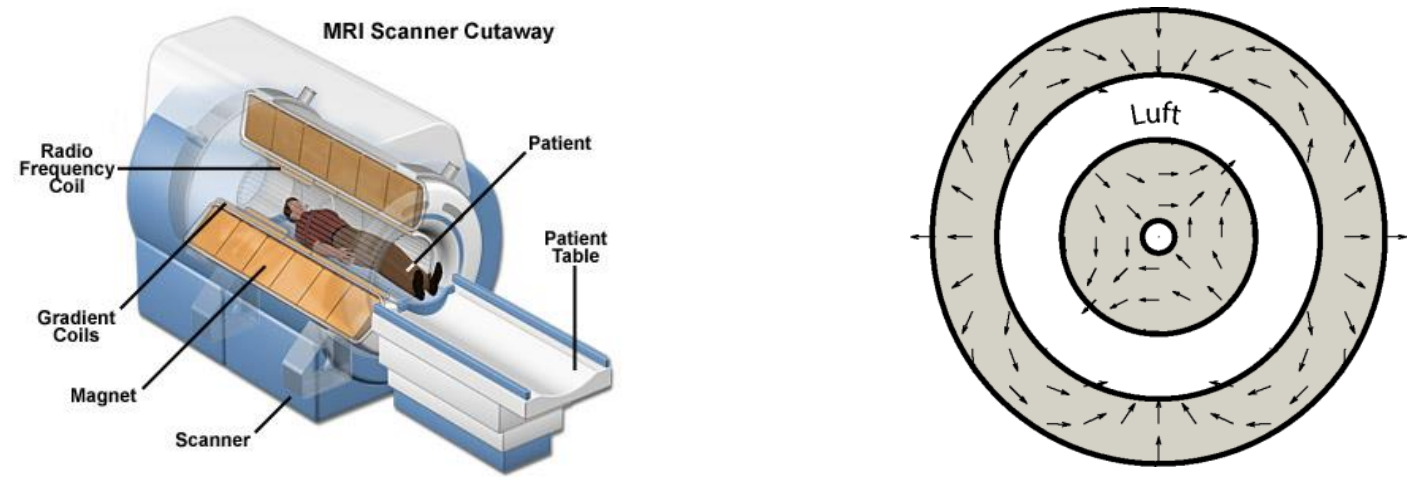

Figure 4. Practical cases of Halbach magnets: MRI scanner (left) and motorbike clutch (right).

This APE-A can be seen as a spin-off from institutional developments at DTU. In 2012, the Department of Energy Conversion and Storage was created by merging a number of previously separate research groups. The new department initially had no students except for supervision of individual master students. To help more students know about the offers of the new area, 
and thereby recruit more graduate students, the department offered to deliver free teaching to certain bachelor level courses, including Mat1.

The course responsible for Mat1 organised a meeting with a representative, $A$, of the new department. Examples and principles of the assignments (APE-A) were presented and a brainstorm on possible contributions from the department took place. Subsequently, $A$ talked to a colleague and office-mate $B$, and then the topic Halbach magnets came up. $B$ had just published a paper on the subject (with the cases above, R. Bjørk et al., 2014) and $A$ could then write a first, rough draft of an APE-A by more or less cutting out the solutions presented in the paper, and replacing them with properly introduced exercises. A second version, done with a Mat1-teacher $C$, followed up on the third practical design rule (mentioned above) by adding a set of preliminary exercises on how to compute the magnetic field induced by a straight and infinitely long conductor; this can be seen as a toy case of the much more complicated calculation of fields induced by Halbach magnets.

This version was then used in the course. Both $A$ and $B$ participated as supervisors in the student project work, both to support the students' work with an APE-A that had not been tested before, and to allow them to get first-hand experience of how it worked in the hands of students. Indeed, the first test found students in serious problems with the first part, since they had just learned basic vector calculus, but not with cylindrical coordinates. Students had to learn this new topic together with elements of electromagnetism, which exemplifies the problem behind the practical design rule 1 .

In the second version to be used, $C$ added a set of purely mathematical exercises on cylindrical coordinates and the special notation used later on. But the last part of the APE-A did still not realize the original intention of $A$ and $B$, namely that students would be led to autonomously experiment the moment of force created in different cases of interactions between two Halbach magnets. It was only in the third tested version that the two practical examples were introduced in order to give students concrete cases (and applications) to work on.

We note that when the assignments undergo major revisions, as in the early years of this case, there is less risk of student copying or otherwise abusing solutions from previous years. Later on, when an APE-A needs only minor revisions, the risk increases and has sometimes been observed by external examiners. Within the last decade, the practice has been not to use the same for more than two years in a row, after which it is archived and subsequently reused some years later. Also, in the design process, authors are encouraged to indicate possible variations for later use.

\section{Case 2: Heat flow in house - simulation and dimensioning}

The abstract APE here is to design the insulation and heating of a house with rooms that should have stable temperature, in spite of the variations of outside temperature. In the concrete APE considered by this assignment, the house has three rooms with different shares of the outer walls, as shown in Figure 5. 

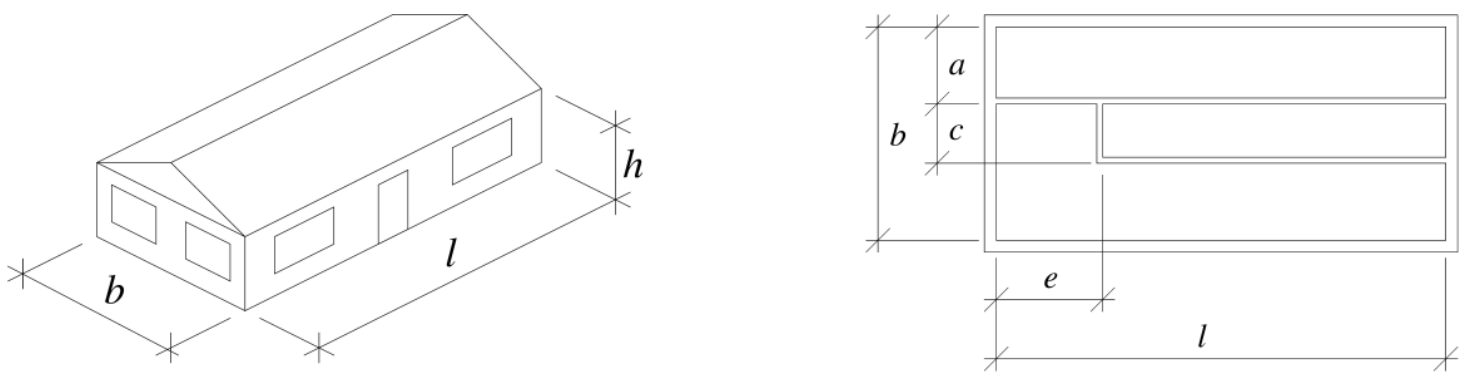

Figure 5. Dimensions of a house (left) and its rooms (right).

The first part of the APE-A concerns modeling the time wise variation of in-house temperature, based on realistic data of the heat transmission coefficients of the different components of the building, and an assumed sinusoidal variation of the outside temperature. The model is gradually made more complex, taking into account the in-house walls, and that the windows of the house have different exposure to sunlight; and the energy needed to maintain a given mean temperature is computed. Then follows a series of exercises on the consequences of varying components of the building, such as the thickness and insolation of the walls - for instance, to determine what is needed to halve the indoor temperature variation. Finally, actual data on the price of heating and insulation is given and the students have to work on balancing initial investment and operating costs, for instance what insolation thickness allows to minimize the total costs over a certain period of time. The mathematical models are essentially systems of differential equations that are solved (in part numerically) using Maple, with the usual applications of matrix algebra as intermediate steps.

This APE was identified during the campaign 2004-2006 (mentioned above). At that time, it proved particularly difficult to create a minimal inventory of APE-A for the areas of civil engineering, in spite of contacting several key figures from this area. A meeting between the campaign organizer (whom we call $D$ here) and the director of the relevant department (DTU Byg) led to more fruitful contacts. A faculty member from DTU Byg pointed out one of his recently published papers (Nielsen, 2005) as containing a possible APE, since the mathematical model was based on topics from Mat1. The central partner from DTU Byg became a PhD-student of Nielsen, whom we call $E$. The PhD-thesis of $E$ was about simulation based optimization problems in the physics of buildings. He delivered all the illustrations, models and data that the final APE-A contained. The APE-A text and exercises were completely drafted by $D$, however in constant interaction with $E$ and his supervisors. In particular, $E$ used his advanced numerical simulation tools to check that the results coming from the simplified model used in the APE-A were not too far from what could be expected under more realistic conditions. Already the first version was very successful, in the sense of offering students appropriate difficulty, and at the same time an APE which is attractive to them; while the experience of $D$ as a teacher on Mat1 ensured the first part, the collaboration with $E$ was crucial to achieve the latter. This APE-A has been used several times with only minor revisions. A current revision work aims at making it more realistic on one point, namely the allowed variation of indoor temperature. This can lead to new variations in the mathematical challenges of the assignment. 


\section{DIDACTIC VARIABLES FOR APE-A DESIGN}

To present and analyse the large number of APE-A's used at DTU within the past 10 years, we have defined ten didactic variables (DV) which are relevant to analyse the assignments according to the aims which have been explicitly pursued in the design work (see Table 1). Each variable has, in principle, a non-numerical range, but can be determined with relatively high objectivity for each assignment, based on its text. The variables were initially formulated by the authors (based on the first authors' many years of involvement in the design) and subsequently validated and adapted during the actual analysis of assignments. Here, validation of a variable occurs when it makes sense in relation to all the assignments, while adaptation is required if it does not. The set of variables was also informally discussed with central colleagues involved in Mat 1, leading to an equally informal validation of the total set as reflecting shared concerns.

The ten variables thus constitute a concrete answer to RQ3, which is of course a partial answer based on experiences from the context we described. Notice that the variables DV4-10 all describe aspects of the relationship between the internal transposition of mathematics represented by the APE-A, and Scholarly Engineering (cf. Figure 1). Their values are thus of specific importance to go beyond the parallel transposition. DV1 and DV2 are more crucial to the role of the APE-A as part of Mat1. Finally we note that the optimal value of DV3 is a matter of considerable debate among the Mat 1 teachers: some consider that students should use Maple whenever that helps them solve a task; others insist on the intrinsic value of students' mastery of basic manual computation. This particular status of DV3, and some of the crucial questions related to it, is reflected in the subvariables DV3a-e (Table 1). 


\section{Didactic variable (DV):}

DV1 What breadth of content areas from Mat1 are needed to solve the assignment? What depth of use?

DV2 What new mathematical contents are introduced?

\section{Aim of designers:}

As many as possible, preferably involving new combinations. Depth beyond standard tasks required.

Contents in continuation of Mat1, not excessive for students to cope with
Maple should mostly be used to:

avoid tedious

- DV3a How essential is the Maple use? computations, and for tasks which the students could not handle otherwise

- DV3d Is there black box use of Maple?

- DV3e What parts of the Maple use are prescribed?

\begin{tabular}{|c|c|}
\hline $\begin{array}{l}\text { DV4. What is the theme and source of the } \\
\text { problem the assignment attacks? }\end{array}$ & $\begin{array}{l}\text { Origin in APE, if possible source in paper or } \\
\text { ongoing research in engineering }\end{array}$ \\
\hline $\begin{array}{l}\text { DV5. Breadth of engineering problem - are } \\
\text { more disciplines involved? }\end{array}$ & $\begin{array}{l}\text { Ideally more than one branch of engineering } \\
\text { involved }\end{array}$ \\
\hline $\begin{array}{l}\text { DV6. How demanding is the mathematical } \\
\text { work on the model that is required from } \\
\text { students? }\end{array}$ & $\begin{array}{l}\text { Ok if model is given in the assignment, but } \\
\text { the students should work intensively with its } \\
\text { mathematical details. }\end{array}$ \\
\hline DV7. How realistic is the model? & As much as possible for the students \\
\hline DV8. How are data used? & Data from the source, used as in the source \\
\hline $\begin{array}{l}\text { DV9. Should the students look up } \\
\text { information outside assignment? }\end{array}$ & $\begin{array}{l}\text { This is not a main aim, except students } \\
\text { should use Mat } 1 \text { course material }\end{array}$ \\
\hline $\begin{array}{l}\text { DV10. How complete are the answers that } \\
\text { the model gives to the main problem? }\end{array}$ & $\begin{array}{l}\text { Clear and definite answers/points, to give } \\
\text { students a satisfying experience }\end{array}$ \\
\hline
\end{tabular}

Table 1. Didactic variables for the analysis of assignments.

The detailed presentations of all APE-A in terms of the variables will not allow for easy comparisons of the assignments. To provide a more handy overview of all APE-A, in terms of the DV, we found it useful to assign indicatory numerical values to the DVs on a scale from 0 to 2 (cf. Table 2). For instance, to assess the breadth of Mat1 contents, which a given assignment requires that the students work with, 0 indicates that only one topic (such as systems of linear equations) is involved, 1 that a few topics from both Calculus and Linear Algebra are involved, and 2 that the assignment combines many topics. Naturally, this grading is not absolute but relative to other assignments. 
In the first two subsections, we analyse the two cases from the previous section in terms of the DV, and explain how the numerical values are determined. We made a similar analysis for all the APE-A used within the past 10 years; the numerical values of DV are discussed in the third subsection (cf. Table 1).

\section{Case 1: Analytical modeling of 2D Halbach permanent magnets}

As may have transpired from our account of its genesis, this APE-A is quite demanding, and involves large and central parts from Mat1. For the model itself, vector calculus (gradient, divergence, curl, Stokes' theorem) is needed - this topic is covered last in the course, just before the project period. Moreover, it is required to solve the partial differential equation in special cases, and the students must use parts of linear algebra from the first half of the course. Thus, clearly DV1 $=2$. But the solution method also involves additional mathematics, such as elements of Fourier series in earlier versions of the APE-A; later versions avoid this by only requiring students to verify a solution. In the latest version, cylindrical coordinates is the main additional mathematics topic in the assignment. We estimate DV2 $=1$.

The presentation and handling of the model is mostly analytic, and Maple only appears to do tedious calculations, like Gaussian elimination in 6x6 matrices with complex symbolic elements, and to visualize the various magnetic fields, which in fact has high technical significance and even aesthetic value. Hence Maple is used according to the stipulated ideal, and $\mathrm{DV} 3=2$.

We consider that DV4 = 1: although the APE comes from a new scientific paper, both the source and (especially the first versions of) the APE-A focus are mainly from basic science (electromagnetic fields). The APE appears only in the last part (and most explicitly in recent versions of the APE-A), as a kind of appendix to the physics model. For the same reason, DV5 = 1 (knowledge from mechanical and medical engineering appears rather superficially), where some real data are used in order to determine dimensions (DV8 $=1$ ).

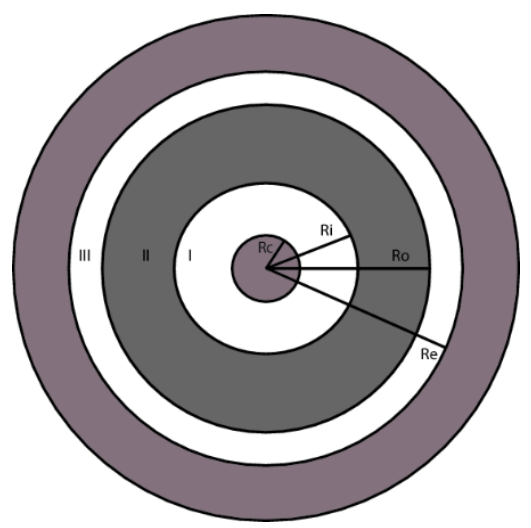

Figure 6. A figure from the assignment "Halbach magnets".

The structure of the APE-A is a long sequence of pre-determined steps which the students are led through, even with rather explicit guidance concerning the modeling of the boundary value problems (the APE), as shown in Figure 6. There, the Halbach magnet is the grey area while the inner and outer shaded rings are made of ideal material with infinite magnetic permeability. 
The constants for a Halbach magnet in air are then determined by letting the inner radius tend to zero and the outer to infinity. All technical tricks in the modeling process are given, but it is very demanding for students to get through all these details. We conclude DV6 $=2$. The models are completely realistic as assumptions and simplifications are identical to the source paper, so DV7 $=2$. As the APE-A contains all information needed to solve it, with no need to search for extra information, DV9 $=0$. The results found are, in principle, complete, so DV10 $=2$, but we must add that an earlier appearance of the APE would make the whole experience more satisfactory; ongoing revisions are aimed at achieving just that.

\section{Case 2: Heat flow in a house}

This assignment is 18 pages long, including about 5 pages of data. But here, the underlying APE is outlined in the very first paragraph:

The building sector accounts for about $40 \%$ of the total energy consumption in Denmark. It is a common assumption that there is a large unrealized potential for reducing the consumption (...) in a financially sound way. To do so requires knowledge of the physical processes which affect the energy consumption of buildings, the financial aspects of the construction and maintenance of buildings, as well as the mathematical methods used to compute these.

The energy flow in a building is modelled as an analogy of currents in electric circuits (cf. Figure 7). The assignment is based on a genuine APE, and the bibliography of the assignment includes a reference to Nielsen (2005), which is the essential source of the whole APE-A (DV4 = 2). The APE-A includes a pricelist from the construction industry, and the last part of the assignment draws on a simple model of investments and interest. Relative to other assignments, this one involves a relatively broad area of Engineering fields, so DV $5=2$. The introduction emphasizes that the model proposed in assignment is "a bit simplified", but in fact it still gives similar results; so DV7 = 2, in spite of some problems (to which we return).

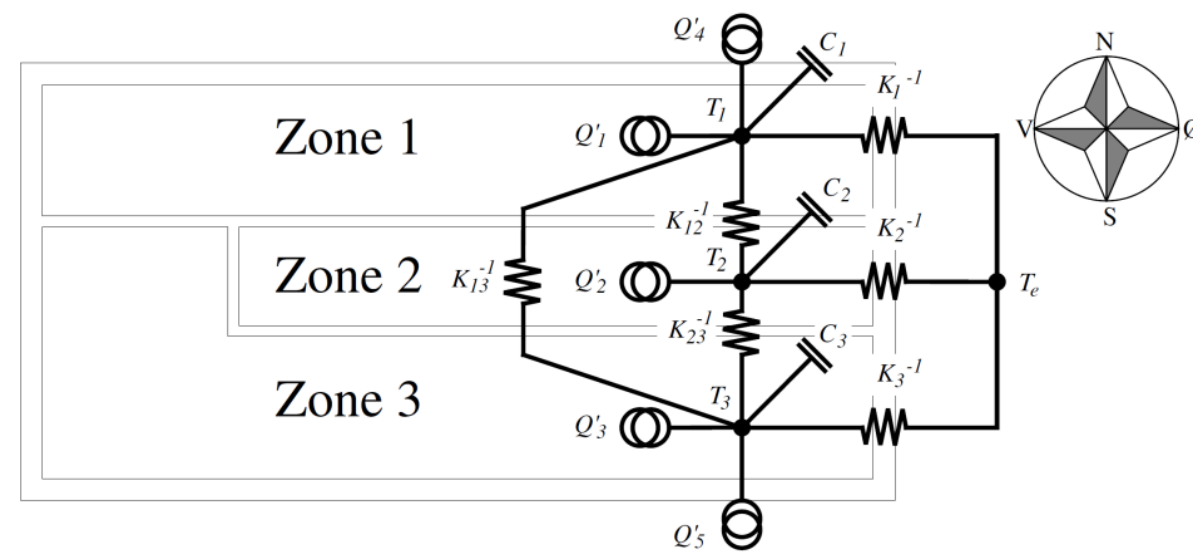

Figure 7. A figure from the assignment "Heat flow in house".

The central model, illustrated in Figure 7, concerns a house with three rooms, called climate zones. Here $Q_{k}^{\prime}$ are the internal and external heat sources (heaters and sunlight), while $C_{k}$ are 
the heat capacities of the rooms and $K_{*}$ are the heat transmission coefficients of the walls of the house, reflecting that these walls involve a variety of layers. Before introducing the final model house, the students work with the simpler case of a one-room house, and an external temperature $T_{e}$ which is a given sine function. Based on further assumptions, and looking at just one room (toy case), this leads to the model for the internal temperature $T_{i}$, as a function of time $t$ :

$$
C \frac{d T_{i}}{d t}=K\left(T_{e}-T_{i}\right)+P\left(T_{s e t}-T_{i}\right)
$$

where $T_{\text {set }}$ is the desired internal temperature (constant), and $P$ is the performance of the internal heat source. While $(*)$ is just a first order ODE, it still gives rise to interesting Engineering tasks: the investigation of stationary solutions, the performance needed to ensure an average temperature of $19.8^{\circ} \mathrm{C}$, and the thickness required to respect given limits on the oscillation of $T_{i}$. The full model consists of a system of three differential equations which are similar to $\left(^{*}\right)$ but with an added complexity due to the heat contribution from sunlight which, moreover, is investigated with two different models. The students must also take into account a model of the walls involving layers of materials to be computed using authentic data. Finally, to take into account the cost of construction, the students are given a simple mathematical model for the total economy involving investment, interest, and operation costs; the mathematics is very simple but still gives rise to interesting questions regarding how to optimize, for instance, insulation thickness. Throughout, the students use real data (DV8=2) but these are all given, so DV9=0. All details of the models are worked on by the students, but the work required from them is not very difficult; thus DV6 $=1$.

The assignment draws on a broad range of Mat1-topics: harmonic oscillations and complex exponential function, single and coupled differential equations, solved using advanced matrix algebra, involving both eigenvalue problems and quadratic forms. Thus DV1 $=2$, while DV2 $=0$ as almost no new mathematics is introduced (the exception being the argument required to justify the stationary solution to the system of differential equations, which involves an extended eigenvalue problem; but here the solution is basically given in the assignment).

While most of the tasks can in principle be solved manually, the visualizations of temperature variations corresponding to different parameter values decisively require a tool like Maple. The assignment moreover invites numeric experimentations, possibly based on graphical representations, and standard use for tedious operations like inversion of matrices, make the overall potential of Maple-use relatively average; we thus assign DV3=1, even if the realized use by some students in some cases goes beyond a mere use of techniques known from the rest of the course.

In real practice, the assignment also suffers from some flaws. Some of the questions lead to less interesting results (like tedious computations leading to a requirement of a four-doubling of the wall thickness in order to reduce an already negligible oscillation of $0.12^{\circ} \mathrm{C}$ for $\left.T_{i}\right)$. More serious is the breakdown of the model when taking into account the contribution of sunshine at low temperatures such as $8^{\circ} \mathrm{C}$, where the stationary answer cannot be found. It can be argued that such problems often arise with simplified models, but it still leaves a negative impression 
on many students, which might be avoided by future revisions. Altogether, we consider DV10 $=1$. As was already mentioned, these flaws are currently being worked on.

\section{Inventory of project assignments}

Table 2 lists the inventory of all assignments used in the last 10 years, analysed using the DVs.

\begin{tabular}{|c|c|c|c|c|c|c|c|c|c|c|}
\hline \multirow[b]{2}{*}{ APE-A name (shortened in a few cases) } & \multicolumn{10}{|c|}{ DV (cf. Table 1) } \\
\hline & 1 & 2 & 3 & 4 & 5 & 6 & 7 & 8 & 9 & 10 \\
\hline Oscillations in Axle-bearing Systems & 2 & 0 & 1 & 2 & 1 & 1 & 2 & 2 & 1 & 2 \\
\hline Micro/Nano Cantilever Based Mass Sensor & 1 & 2 & 1 & 2 & 1 & 1 & 2 & 1 & 1 & 1 \\
\hline Enzymatic Hydrolysis of Cellulose & 1 & 1 & 1 & 0 & 1 & 2 & 1 & 1 & 0 & 1 \\
\hline Modelling 2D Halbach permanent Magnets & 2 & 1 & 2 & 1 & 1 & 2 & 2 & 1 & 0 & 2 \\
\hline Factorization of Integers & 0 & 2 & 2 & 0 & 1 & 0 & 1 & 0 & 0 & 1 \\
\hline Heat flow in house - simulation, dimensioning & 2 & 0 & 2 & 2 & 2 & 1 & 2 & 2 & 0 & 1 \\
\hline Quantum Mechanics in a Nutshell & 2 & 2 & 2 & 2 & 2 & 1 & 2 & 2 & 0 & 1 \\
\hline Red Blood Cells - Optimization in Nature & 1 & 2 & 2 & 1 & 1 & 2 & 1 & 0 & 0 & 2 \\
\hline Utilization of the Waste Product Whey & 1 & 0 & 1 & 2 & 1 & 2 & 1 & 1 & 0 & 2 \\
\hline Forced Pendulum & 1 & 2 & 2 & 1 & 1 & 2 & 1 & 0 & 0 & 2 \\
\hline Stability in Chilled Tank Reactor & 1 & 2 & 1 & 1 & 1 & 1 & 1 & 1 & 0 & 2 \\
\hline Optimization of Work Cycles & 2 & 1 & 2 & 2 & 1 & 1 & 1 & 0 & 0 & 2 \\
\hline GPS and Geometry & 1 & 2 & 2 & 2 & 2 & 1 & 1 & 1 & 2 & 1 \\
\hline Oscillations in Grid Constructions & 2 & 2 & 1 & 2 & 1 & 2 & 1 & 0 & 1 & 1 \\
\hline Groundwater Flow in the Forest Vestskoven & 1 & 2 & 2 & 2 & 1 & 1 & 2 & 2 & 0 & 1 \\
\hline Internet Hit lists & 1 & 2 & 2 & 2 & 1 & 1 & 2 & 2 & 1 & 2 \\
\hline Short Circuit in Electric Networks & 1 & 2 & 2 & 1 & 1 & 1 & 1 & 0 & 0 & 2 \\
\hline Simulation of Stretch Reflex & 1 & 1 & 1 & 2 & 1 & 1 & 1 & 0 & 0 & 1 \\
\hline Parking Orbits of Satellites & 2 & 1 & 0 & 1 & 1 & 2 & 1 & 0 & 1 & 2 \\
\hline Solar Energy Absorption in Curved Glass houses & 2 & 0 & 2 & 1 & 1 & 1 & 1 & 0 & 0 & 1 \\
\hline Flow in Chemical Reactors & 2 & 0 & 1 & 1 & 1 & 2 & 1 & 0 & 1 & 2 \\
\hline Finite elements in One Dimension & 1 & 2 & 2 & 2 & 1 & 2 & 1 & 0 & 1 & 1 \\
\hline Geodesic Curves & 1 & 2 & 2 & 0 & 0 & 2 & 2 & 0 & 0 & 2 \\
\hline The Brains Glycose Metabolism & 1 & 2 & 2 & 2 & 1 & 1 & 2 & 1 & 1 & 1 \\
\hline Resistors and Markov Chains & 1 & 2 & 2 & 1 & 1 & 1 & 1 & 0 & 0 & 2 \\
\hline Dosage of Anaesthesia & 2 & 1 & 1 & 2 & 1 & 2 & 1 & 1 & 0 & 2 \\
\hline Anthrax - Attack, Escape and Rescue & 1 & 2 & 2 & 2 & 1 & 2 & 1 & 1 & 2 & 2 \\
\hline Decomposition of PCE & 1 & 1 & 1 & 2 & 1 & 1 & 1 & 2 & 1 & 0 \\
\hline Modelling Concrete Moulding & 1 & 2 & 2 & 2 & 2 & 1 & 2 & 2 & 2 & 1 \\
\hline Soap Membranes & 1 & 2 & 2 & 1 & 1 & 1 & 2 & 0 & 0 & 1 \\
\hline Distribution of Electrons in Semiconductors & 1 & 2 & 2 & 1 & 1 & 1 & 2 & 0 & 0 & 1 \\
\hline
\end{tabular}


A number of interesting tendencies can be identified in Table 2, including relatively high correlation of DV4 and DV5 (45\%, reflecting that APEs tend to involve more disciplines) and also of DV4 and DV9 (43\%, reflecting that APE-As originating in APE are relatively likely to require that students look up external information). Still, only DV1 and DV2 carry a (negative) correlation of value higher than $50 \%$, reflecting that new mathematical contents can be introduced at the expense of involving a breadth of contents already covered by the course. In fact, the variables are altogether relatively independent (mean absolute correlation about $20 \%$ ), for the inventory of APE-A analysed here.

There are two variables which appear overall low (DV8 and DV9), corresponding to relatively little use of authentic data and external information to be looked up. We stress, however, that a simple sum of the values of didactic variables, for a specific assignment, cannot be construed as a measure of the didactic quality of the assignment. One reason is that the variables are not of equal importance (in particular, DV1, 4 and 10 are essential). But more importantly, one cannot always construe a 2 as being objectively the best possible value of the DV; the aims listed in Table 1 are open to debate and the viewpoint of teachers and designers may differ. A good example is DV4, where we have given 2 for assignments with a clear APE, 1 for assignments with an authentic problem from basic science (e.g. Chemistry) and 0 for assignments which are not based on an APE but on a (prima facie) purely mathematical problem, such as the assignment "Geodesic curves". One can argue that an assignment with DV4 $=0$ can also be of high quality as an assignment for future engineers, in view of the importance in several branches of the mathematical problem (in the example, DV2 $=2$ and indeed, geodesic curves have multiple applications in many branches of engineering, see e.g. Patrikalaksis and Maekawa, 2010, 265-291). A similar uncertainty must also be pointed out for other variables such as DV3, where the further graduation suggested in Table 1 could be useful to provide a more nuanced picture than the analysis in Table 2 (cf. our treatment of Case 1 above).

\section{CONCLUSIONS}

We have presented the principles, processes and products of a relatively longstanding effort to integrate elements of scholarly Engineering (APEs) in the internal didactic transposition of mathematics in a course that caters to a wide range of Engineering programmes, to yield student assignments that go well beyond isolated applications of Calculus or Linear Algebra. 
We have emphasised the multiple dimensions which such an effort needs to consider, in order to maintain the link with the mathematical knowledge to be taught within the module in question, and at the same time, establish non-trivial links with Scholarly Engineering (cf. Figure 1).

As for RQ1, we have emphasised the need for an institutionally endorsed framework to allow collaboration between mathematics and engineering partners, and also (at least in the institutional context of DTU) for this collaboration to be initiated by a dynamic mathematician who is familiar both with scholarly work in Engineering and with the contents and context of the mathematics course. The overall effort to involve genuine APEs is reflected in the mean of DV4 (1.5). At the same time, one must not forget two central qualities of assignments in a mathematics course, namely that they can be solved in a manner that centrally involves known mathematics, and that they offer opportunities to learn new mathematics. The focus on these challenges during the design process is reflected in the mean values of DV1 (1.2) and DV2 (1.4), respectively.

When it comes to RQ2, we emphasize the four "practical rules" for the design process early on, while formulated together by us, as a result of piecing together various documents and elements of interviews. These practical rules have been in function throughout the twenty years of experience at DTU and could inform and inspire practitioners elsewhere who consider embarking on designing APE-A for similar mathematics courses. The same can be said about the presented outline of the process of building up and maintaining a viable inventory of APEA's, so that one does not have to design all assignments from scratch every year. At the same time we point out the need, at least in this context, of proceeding without too much delay to implementation, given that the returns from observation and evaluation have been crucial to develop some of the most interesting and ambitious assignments into a more stable, yet not permanent form. As illustrated by Case 1, one may want to start out with somewhat daring assignments, to adapt to real rather than imaginary difficulty for students. In fact, overly scaffolding students' work may not offer them a satisfying experience of solving an APE (even if some scaffolding may prove necessary). We finally emphasize that the linear design model suggested by Figure 2 should not be taken too literally, but as a first approximation. In fact, later revisions may also involve the scholarly institution when it comes to validate variations and exemplifications of the APE, as illustrated by Case 1 .

To answer RQ3, we have proposed and demonstrated the use of a possible set of DV. Certainly, the set of variables presented here can be developed and adapted further, and we believe that such variables can become a valuable, explicit basis for the discussion of aims (right column in Table 1) of APE-A at DTU and in other institutional and didactical contexts in which they could be relevant. In fact, developing such explicit variables appears to be an important tool for systematizing the design process, both as a check list for constructing new assignments and (in combination with the analyses behind Table 2) to identify potentials for enriching existing assignments. We expect that the variables will also become useful guidelines for investigating the effects of the project work in this course as a means to facilitate the transition to later 
courses where mathematics is so fully integrated into the engineering knowledge to be taught that the latter is in practice as inseparable from mathematics as music is from sound.

\section{NOTE}

On behalf of both authors, the corresponding author states that there is no conflict of interest.

\section{REFERENCES}

Baillie, C. and Fitzgerald, G. (2000). Motivation and attrition in engineering students. European Journal of Engineering Education 25(2), 145-155.

Bergqvist, E. (2007). Types of reasoning required in university exams in mathematics in Sweden. Journal of Mathematical Behavior, 26(4), 348-370.

R. Bjørk, C. R. H. Bahl, A. Smith and N. Pryds (2014). Analysis of the magnetic field, force, and torque for two-dimensional Halbach cylinders. Journal of Magnetism and Magnetic Materials 322 (1), 133-141.

Castela, C. and Romo-Vásquez, A. (2011). Des mathématiques à l'automatique: étude des effets de transposition sur la transformée de Laplace dans la formation des ingénieurs. Recherches en didactique des mathématiques 31(1), 79-130.

Chevallard, Y. (1991). La Transposition didactique: du savoir savant au savoir enseigné $\left(2^{\text {nd }}\right.$ edition). Grenoble: La Pensée Sauvage.

Chevallard, Y. (1999). L'analyse des pratiques enseignantes en théorie anthropologique du didactique. Recherches en Didactique des Mathématiques 19(2), 221-266.

Chevallard, Y. (2019). Introducing the anthropological theory of the didactic: an attempt at a principled approach. Hiroshima Journal of Mathematics Education 12: 71-114.

Flegg, J., Mallet, D. and Lupton, M. (2012) Students' perceptions of the relevance of mathematics in engineering. International Journal of Mathematical Education in Science and Technology 43(6), 717-732.

Halbach, K. (1980). Design of permanent multipole magnets with oriented rare earth cobalt material. Nuclear instruments and methods 169, 1-10.

Hardy, N. (2009). Students' perceptions of institutional practices: the case of limits of functions in college level Calculus courses. Educational Studies in Mathematics 72(3), 341-358.

Harris, D., Black, L., Hernandez-Martinez, P., Pepin, B. and Williams J. (2015). Mathematics and its value for engineering students: what are the implications for teaching? International Journal of Mathematical Education in Science and Technology 46 (3), 321-336.

Härterich, J., Kiss, C., Rooch, A., Mönnigmann, M., Darup, M. and Span, R. (2012). MathePraxis connecting first-year mathematics with engineering applications. European Journal of Engineering Education 37(3), 255-266. 
Kumar, S. and Jalkio, J. (1999). Teaching mathematics from an application perspective. Journal of Engineering Education July 1999, 275-279.

Mustoe, L. (2002) Mathematics in engineering education, European Journal of Engineering Education 27(3), 237-240.

Nielsen, T. R. (2005). Simple tool to evaluate energy demand and indoor environment in the early stages of building design. Solar Energy 78(1), 73-78.

Patrikalaksis, N. and Maekawa, T. (2010). Shape Interrogation for Computer Aided Design and Manufacturing. Berlin, Heidelberg: Springer.

Pojholainen, S., Myllykoski, T., Mercat, C. and Sosnovsky, S. (2018, Eds.), Modern mathematics education for engineering currcicula in Europe. Bern: Birkåhäuser.

Ruthven, K. (2018). Taking design to task: a critical appreciation. In: Watson, A. and Ohtani, M. (2018, Eds.). Task design in mathematics education, pp. 311-320). London: Springer.

Schmidt, K. and Winsløw, C. (2018). Task design for engineering mathematics: process, principles and products. In: V. Durand-Guerrier, R. Hochmuth, S. Goodchild \& N.M Hogstad (Eds.), Proceedings of the Second Conference of the International Network for Didactic Research in University Mathematics, pp. 165-174. Kristiansand: University of Agder.

Watson, A. and Ohtani, M. (2015). Task design in mathematics education: an ICMI study. Cham: Springer.

Wolf, P. and Biehler, R. (2016). Anwendungsorientierte Aufgaben für die ErstsemesterMathematik-Veranstaltungen im Maschinenbaustudium (V.2). KHDM report 16-04. Retrieved from http://nbn-resolving.de/urn:nbn:de:hebis:34-2016010549550

Wolf, P. (2017). Anwendungsorientierte Aufgaben für Mathematikveranstaltungen der Ingenieurstudiengänge: Konzeptgeleitete Entwicklung und Erprobung am Beispiel des Maschinenbaustudiengangs im ersten Studienjahr. Wiesbaden: Springer. 